\title{
Microstructure Evolution of a Nickel-Base Alloy Resistant to High Temperature during Aging
}

\author{
Alberto Carlos Picasso, César Armando Lanz, Matías Sosa Lissarrague, \\ Aldo Daniel Garófoli \\ Comisión de Investigaciones Científicas de la Provincia de Buenos Aires (CICPBA), \\ Universidad Nacional del Sur, Bahía Blanca, Argentina \\ Email: alberto.picasso@uns.edu.ar
}

Received 14 December 2015; accepted 25 January 2016; published 28 January 2016

Copyright (C) 2016 by authors and Scientific Research Publishing Inc.

This work is licensed under the Creative Commons Attribution International License (CC BY). http://creativecommons.org/licenses/by/4.0/

c) (7) Open Access

\begin{abstract}
In the present study, the microstructural evolution during aging at 1023, 1073, 1123 and $1173 \mathrm{~K}$ of a $35 \mathrm{Cr}-45 \mathrm{Ni}$ heat resistant alloy, produced in the form of centrifugally cast tubes, was characterized by means of light optical microscopy, scanning electron microscopy (SEM) with secondary and backscattered electron imaging, energy-dispersive X-ray spectroscopy (EDS) and Vickers hardness tests. The evolution of the Vickers hardness at $1023 \mathrm{~K}$ for aged samples shows that the microstructure is stable during the analyzed aging period. At $1073 \mathrm{~K}$, the rate of increase in hardness is lower than $1023 \mathrm{~K}$ and this behavior would be associated with morphological changes observed in primary interdendritic carbides and secondary carbides in the matrix. At $1123 \mathrm{~K}$ and $1173 \mathrm{~K}$, an atypical behavior in Vickers hardness curve is presented; where it can be seen that at certain aging times, the hardness decreases significantly. A microstructural analysis of these samples indicates that they have a region free of precipitates (near interdendritic edges) where the hardness is lower. Probably, these regions are areas poor in chromium.
\end{abstract}

Keywords

Microstructural Characterization, 35Cr-45Ni Alloy, Aging, Precipitation, Depleted Zones

\section{Introduction}

Iron and nickel-based alloys are used for pressure vessels, piping, fittings, valves and other equipment in refineries and petrochemical plants. A large percentage of the applications for stainless steels and heat resistant mate- 
rials above $923 \mathrm{~K}$ are in connection with fired heater. The principle selection criteria applied to materials for refining and petrochemical plant equipment include, but are not necessarily limited to, the following: a) mechanical properties, b) corrosion resistance, c) stability of mechanical properties, d) fabricability, e) availability and f) cost [1]. Wide varieties of these alloys have been produced by centrifugal casting for more than 50 years and are used in conditions that involve high pressures and temperatures. Early works involve alloys of the HK type (25Cr-20Ni), being followed later by the HP type (25Cr-35Ni). Demands for the reduction in fuel and emissions impose harsher operating conditions in many industrial sectors, and so the development of a new generation of heat resistant alloys with contents of $35 \% \mathrm{Cr}$ and $45 \% \mathrm{Ni}$, as well as many other elements. These alloys are materials designed to withstand oxidizing and corrosive environments in sustained operation at temperatures greater than $923 \mathrm{~K}$; most of these materials are cast from melts rich in iron, chromium, and nickel. Elements such as niobium, titanium, vanadium, and zirconium are commonly added to impart higher creep resistance, as they form stable precipitates at the operating temperatures. On the other hand, silicon and manganese are added to increase resistance to different degrading atmospheres. Due to their exceptional resistance to carburization and oxidation of up to $1422 \mathrm{~K}$, heat resistant alloys are used for manufacturing tubes, flanges, cones, harps, headers and coils in furnaces, transfer lines, heaters, and other appliances, for direct reduction of iron ore plants, petrochemical, chemical, and commercial heat treating industries [2]-[5]. The typical microstructure of as-cast Ni-CrFe alloys is an austenite matrix with intergranular eutectic-like primary chromium-rich carbides $\left(\mathrm{M}_{7} \mathrm{C}_{3}\right.$ and/or $\mathrm{M}_{23} \mathrm{C}_{6}$ types) and niobium carbides (MC type). During service at temperatures of 1023 - $1373 \mathrm{~K}$, the primary chromium carbides eventually transform into $\mathrm{M}_{23} \mathrm{C}_{6}$; intragranular secondary $\mathrm{M}_{23} \mathrm{C}_{6}$ carbides also precipitate. In spite of being designed to have a long life, these materials fail for reasons associated with the instability in their microstructure. One of the most noted and analyzed by different authors is the transformation of primary MC carbides in silicides, known as $\mathrm{G}$ phase $\left(\mathrm{Ni}_{16} \mathrm{Nb}_{6} \mathrm{Si}_{7}\right)$, which is presented as a fragile phase that affects the creep behavior under service. The aim of this study was to characterize the microstructural evolution of 35Cr-45Ni alloy aged at 1023, 1073, 1123 and $1173 \mathrm{~K}$ at different times, from observations by optical microscopy (OM), scanning electron microscopy (SEM) and determination of macro and Vickers microhardness.

\section{Experimental Procedure}

The alloy was produced as centrifugally cast pipes by a conventional procedure, with a $110 \mathrm{~mm}$ diameter and a $11 \mathrm{~mm}$ wall thickness. Specimens of cast material were obtained from a ring extracted of the tube and cut transversely with a $12 \mathrm{~mm}$ width.

The chemical composition of the Ni-Cr-Fe alloy studied is indicated in Table 1.

The aging temperatures were 1023, 1073, 1123 and $1173 \mathrm{~K}$ and aging times of up to 4000, 2000, 3000 and $1000 \mathrm{~h}$, respectively. Aging heat treatment was made using resistive furnaces in air atmosphere, and then each sample was cooled in air. The samples were ground with silicon carbide papers from 80 to 2000 grit. Polishing was done with $1 \mu \mathrm{m}$ alumina paste. Polished specimens were electrolytically etched with a $10 \%$ aqueous solution of $\mathrm{KOH}$. Metallographic observations were made with a Leica light microscopy equipped with a DFC 295CCD camera. The identification of primary and secondary particles was done using scanning electron microscopy (SEM) in secondary electrons mode (SE) and back-scattered electron imaging mode (BSE) and electron probe micro-analysis with energy-dispersive X-ray spectroscopy (EDS). It was determined Vickers hardness (macro) and Vickers microhardness using an OSHMA hardness tester with a load of $1 \mathrm{kgf}$ and a Future Tech FM300 series microhardness tester using a load of $10 \mathrm{~g}$, respectively. The Vickers hardness determined for a given temperature and time, corresponds to a single sample.

\section{Results and Discussion}

\subsection{Microstructural Characterization of As-Cast Material}

Figure 1 shows low magnification micrographs of centrifugally cast microstructures of the studied alloy, where the austenite matrix with intergranular eutectic like primary carbides can be seen.

Table 1. Chemical composition of the studied alloy.

\begin{tabular}{ccccccccc}
\hline $\mathrm{C}$ & $\mathrm{Si}$ & $\mathrm{Mn}$ & $\mathrm{Ni}$ & $\mathrm{Cr}$ & $\mathrm{Fe}$ & $\mathrm{Nb}$ & $\mathrm{Ti}+\mathrm{Zr}$ \\
\hline 0.45 & 1.60 & 1.00 & 45.00 & 35.00 & 16.00 & 1.00 & $<0.09$ \\
\hline
\end{tabular}




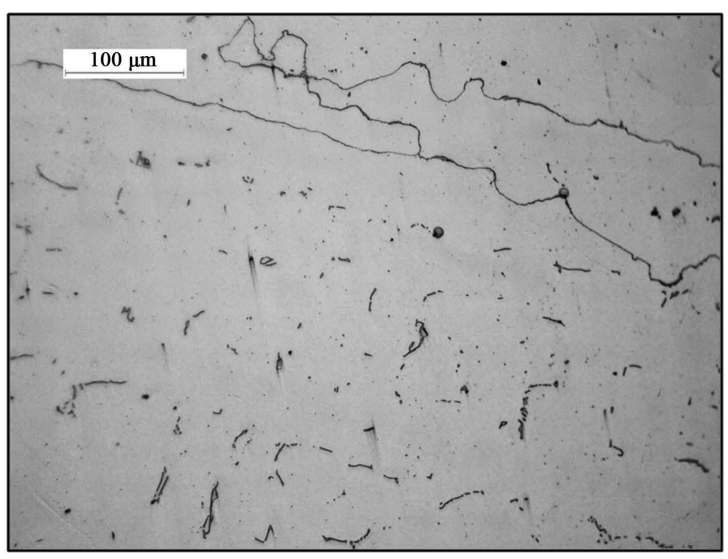

(a)

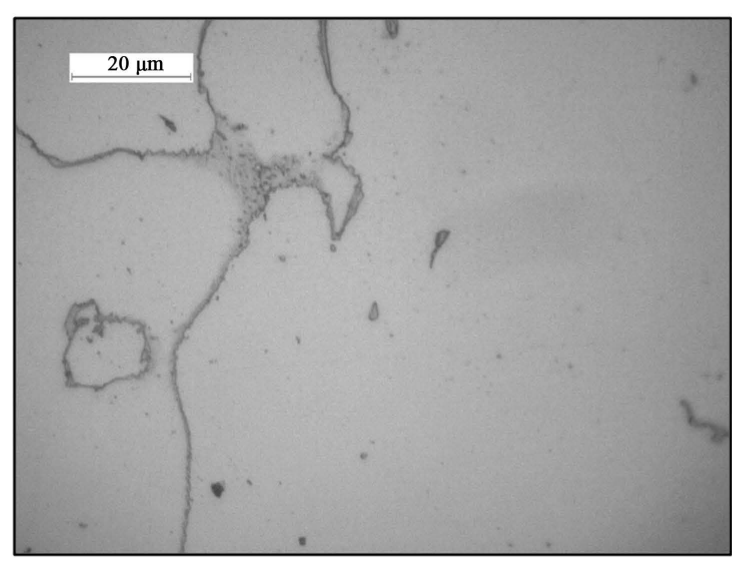

(b)

Figure 1. Microstructure of as-cast alloy tube: (a) OM image at low magnification (200×) and (b) OM image at high magnification (1000×).

Using SEM (Q4) in the SE and BSE, it is easy to observe differences between chromium-rich carbides $\left(\mathrm{M}_{23} \mathrm{C}_{6}\right.$ and $\mathrm{M}_{7} \mathrm{C}_{3}$ ) and niobium-rich carbides (MC). Indeed, on back-scattered electron images, the bright niobiumcontaining phases can be distinguished easily from the dark grey chromium-rich phases. Nevertheless, this technique cannot differentiate $\mathrm{M}_{23} \mathrm{C}_{6}$ from $\mathrm{M}_{7} \mathrm{C}_{3}$, because they have similar electronic densities (1.96 electrons/ $\AA^{3}$ for $\mathrm{Cr}_{23} \mathrm{C}_{6}$ and 1.92 electrons $/ \AA^{3}$ for $\mathrm{Cr}_{7} \mathrm{C}_{3}$ ) and therefore similar chemical contrasts in BSE. Figure 2 shows SEM observation in the SE and BSE mode of the microstructure as-cast.

$\mathrm{X}$-ray analyses of these carbides were also obtained (EDS) (Figure 3).

$\mathrm{X}$-ray diffraction analyses were carried out on a sample in their as-cast condition (Figure 4).

The microstructure of the as-cast alloy is composed by austenitic matrix and a network of primary carbides of two types: MC carbides $(\mathrm{M}=\mathrm{Nb}, \mathrm{Ti})$ and M7C3 carbides $(\mathrm{M}=\mathrm{Cr}, \mathrm{Ni}, \mathrm{Fe})$. In addition, it is observed that both types of carbides present different morphologies. The $\mathrm{M}_{7} \mathrm{C}_{3}$ types show morphological characteristics of a eutectic composite; whilst the MC types have a more regular morphology. Several authors [6]-[10], have noted that these carbides cannot be distinguished by optical microscopy, it is necessary to resort to using a backscattered electrons SEM micrograph.

\subsection{Effect of Aging Treatment on the Microstructure at T = $1023 \mathrm{~K}$}

In Figure 5, the respective microstructures are presented corresponding to aging treatments performed at $\mathrm{T}=$ $1023 \mathrm{~K}$ and different aging times.

Regarding the as-cast microstructure, the aged samples show a microstructure in which the following can be observed: a) initiation and growth of secondary precipitation in the matrix (increase in area fraction) as a function of the aging time, b) secondary precipitation initiated in the interdendritic regions near edges and grain boundaries and ingrowth of dendrites, iii) morphology in the secondary precipitates of needle type with a welldefined orientation.

A detailed analysis of the secondary particles by X-ray scattering indicated that these particles are rich in Cr. Figure 6 shows an X-ray spectrum obtained for these particles.

Some authors [6], studied the aging $1023 \mathrm{~K}$ in an alloy very similar to ours and found that the precipitated secondary particles were needle-shaped carbides of $\mathrm{M}_{23} \mathrm{C}_{6}(\mathrm{M}=\mathrm{Cr})$ type and distributed homogeneously with orientation on (110) planes. Similarly, [11] determined that during ageing $1023 \mathrm{~K}$ conducted in high-temperature-resistant alloy of the 35Cr-45Ni type, carbides $\mathrm{M}_{23} \mathrm{C}_{6}$ type $(\mathrm{M}=\mathrm{Cr})$ precipitated in the matrix and in a similar arrangement to that observed in our case. Thus, we assume that the carbides in the matrix found in our case were $\mathrm{M}_{23} \mathrm{C}_{6}$ type carbides (with $\mathrm{M}=\mathrm{Cr}, \mathrm{Ni}, \mathrm{Fe}$ ). On the other hand, in certain austenitic stainless steels, the carbides of the type $\mathrm{M}_{23} \mathrm{C}_{6}$ are found to lie in strings along $<110>$ matrix directions. Studies of the early stages of ageing have shown that discrete particles are nucleated on the existing dislocations, and they grow partially coherently with the matrix. In order to accommodate the strains resulting from the difference in atomic volume between the two lattices, prismatic loops of dislocation are punched out by the growing particle into the matrix. 


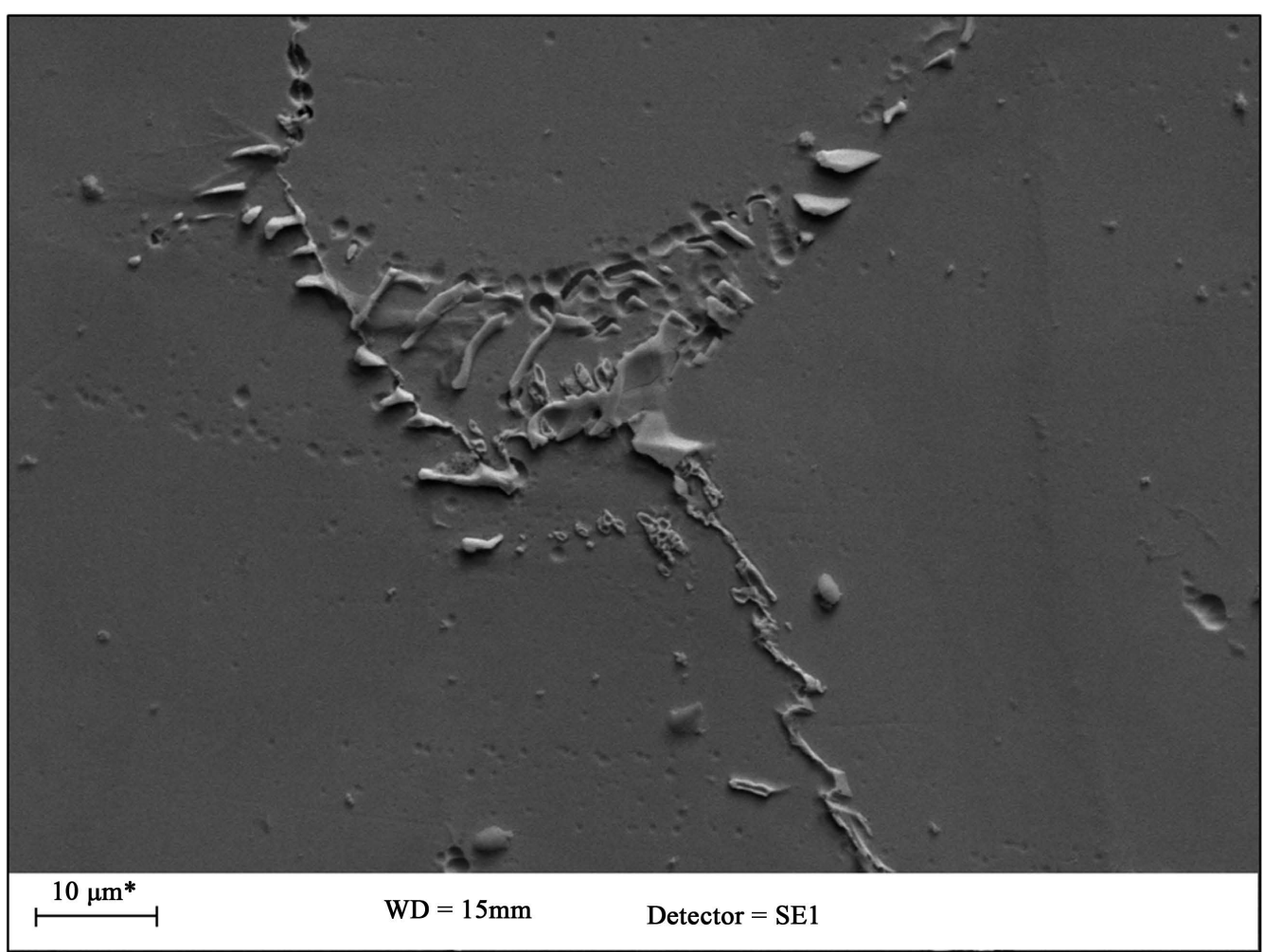

(a)

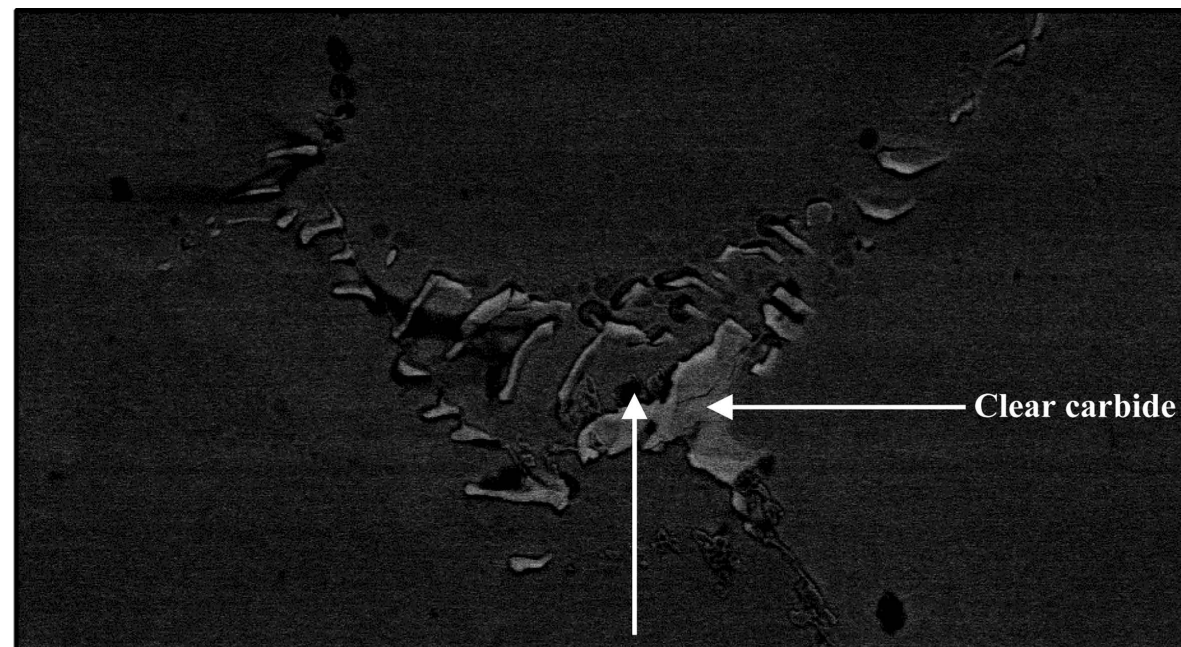

Dark carbide

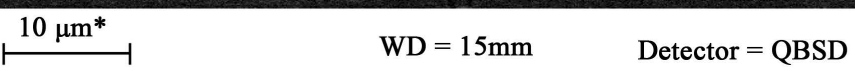

(b)

Figure 2. SEM images of as-cast alloy tube (3000×): (a) as-cast shown using secondary electrons; (b) ascast shown using backscattered electrons. 

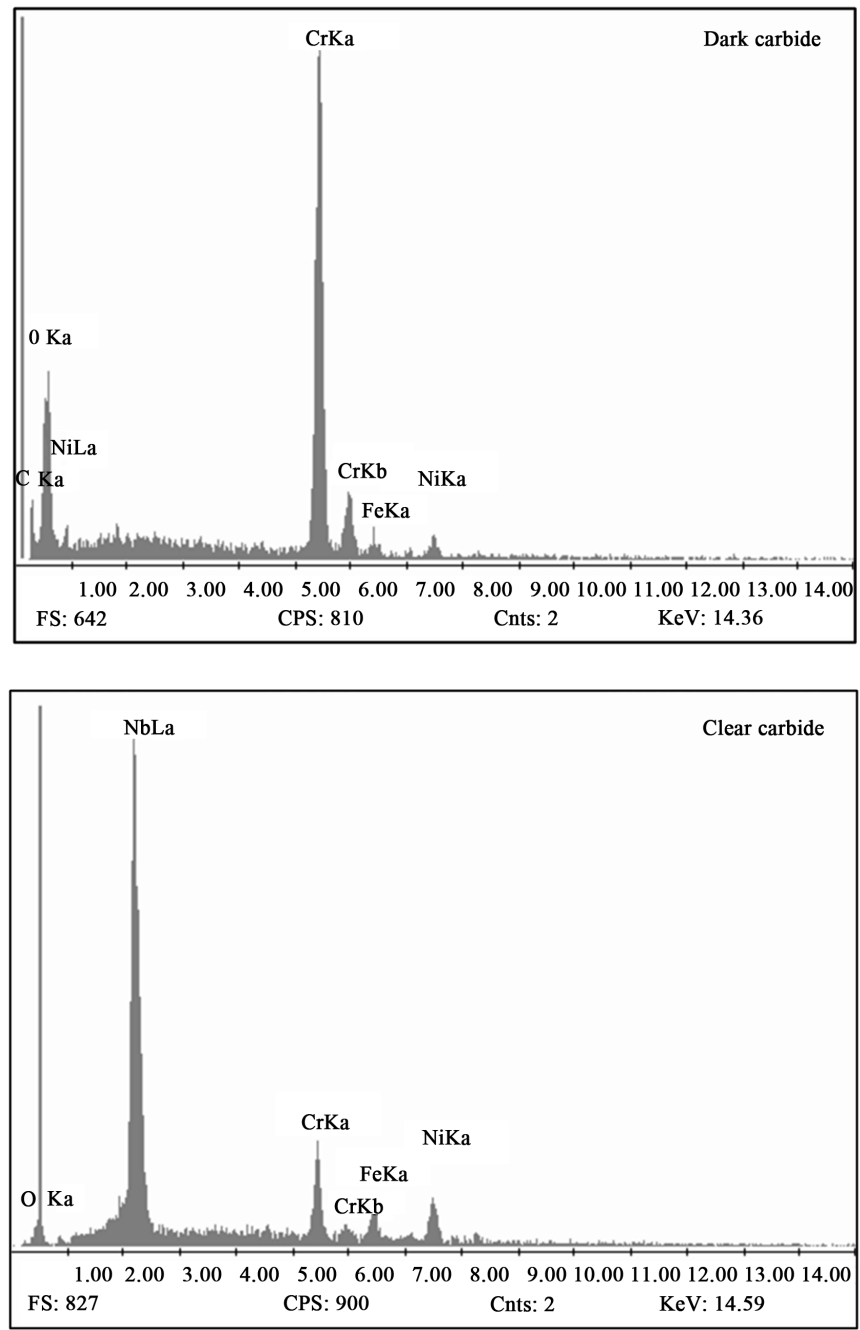

Figure 3. Spectra obtained by punctual analysis in the dark and clear carbides shown in Figure 2(b).

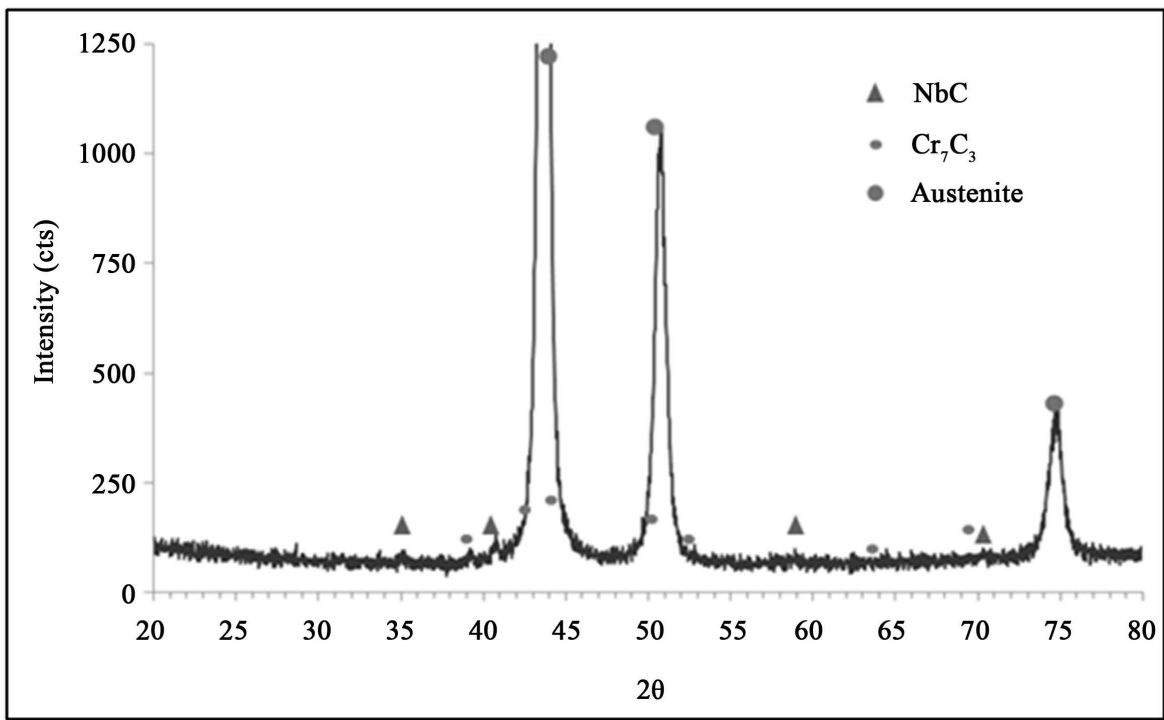

Figure 4. X-ray diffraction charts in as-cast. 


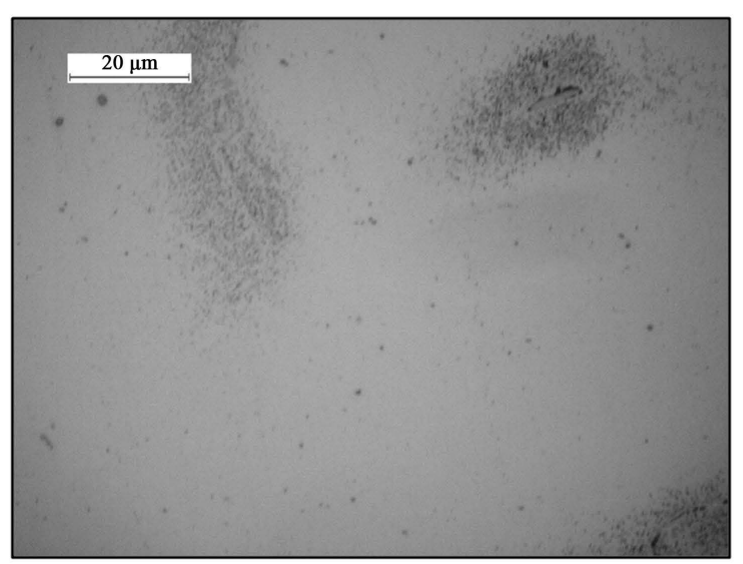

(a)

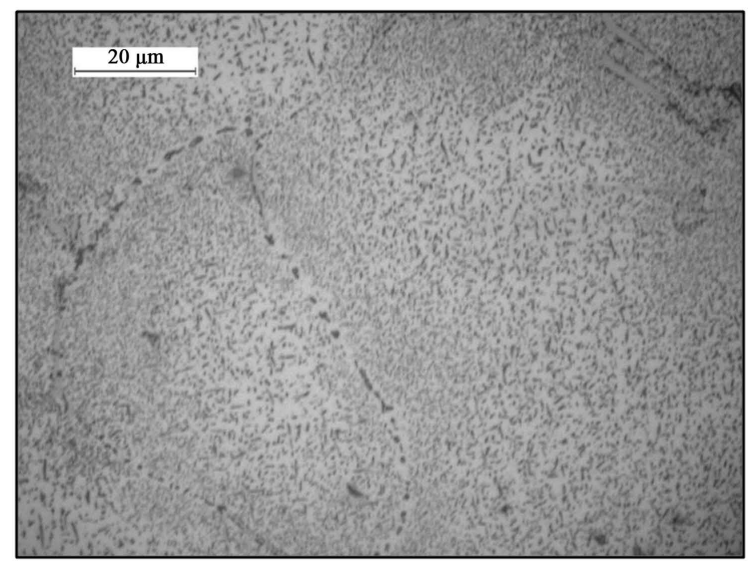

(c)

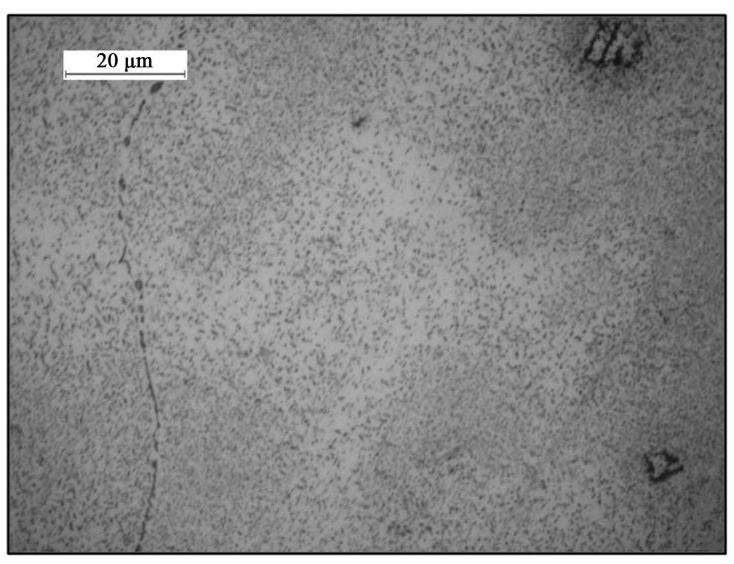

(b)

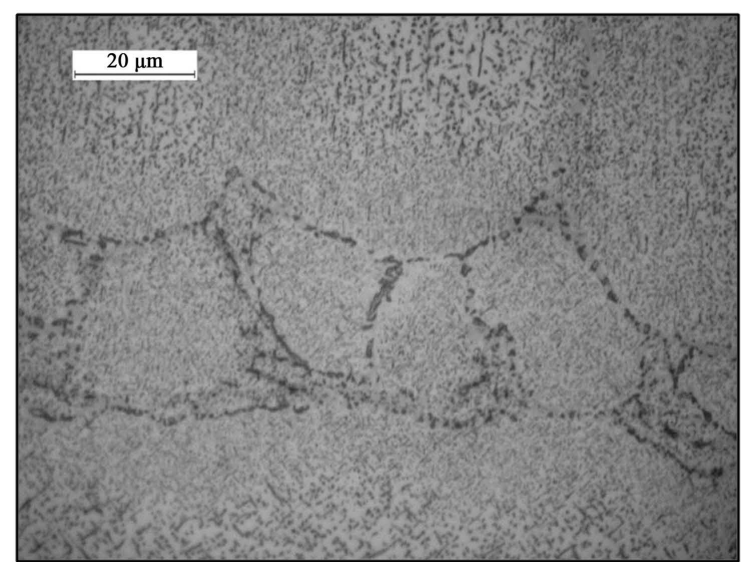

(d)

Figure 5. Microstructure of alloy after aging treatments to $\mathrm{T}=1023 \mathrm{~K}$ with different time (1000×): (a) $98 \mathrm{~h}$, (b) $479 \mathrm{~h}$, (c) $1640 \mathrm{~h}$, and (d) $3992 \mathrm{~h}$.

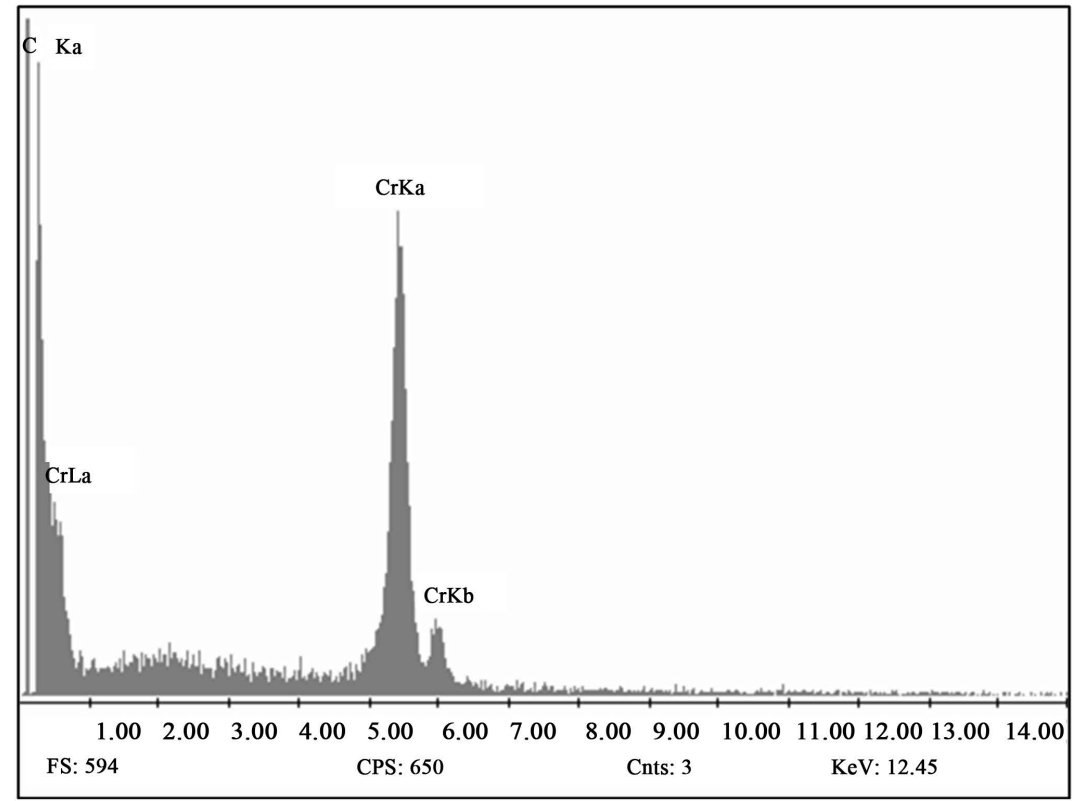

Figure 6. X-ray spectrum corresponding to the secondary particles precipitated in the matrix. 
These punched loops (which have $<110>$ glide axes) then act as sites for further precipitation of carbide, resulting in the formation of the stringers observed after long ageing times [12].

\subsection{Evolution of the Hardness during the Aging at $1023 \mathrm{~K}$}

In Figure 7, the evolution of the Vickers macrohardness is presented as a function of aging time for $\mathrm{T}=1023 \mathrm{~K}$.

It is noted that Vickers macrohardness increases with aging time from its as-cast condition $(\mathrm{Hv}=173)$ to a value of about 250 and then, remains, approximately, constant. Clearly, growth hardness is associated with the increase of the volume fraction of secondary precipitation. Subsequently, hardness values determined for time near $4000 \mathrm{~h}$ aging processes could indicate that the Vickers hardness is maintained constant.

\subsection{Effect of Aging Treatment on the Microstructure at $\mathrm{T}=1073 \mathrm{~K}$}

In Figure 8, the corresponding microstructures are presented at different aging times for samples heat treated at $\mathrm{T}=1073 \mathrm{~K}$.

In this case, a similar microstructure to the previous case can be observed, with a small difference that is characteristic in some samples. It was found that some samples show a zone free of precipitates near the grain boundary; as indicated in the previous figure. Also, regions may be observed within the dendrites where the volume fraction of secondary precipitates is very low. It is likely that this phenomenon is associated with the low carbon concentration in that region.

\subsection{Evolution of the Hardness during the Aging at $1073 \mathrm{~K}$}

Figure 9 shows the evolution of the Vickers macrohardness as a function of aging time for samples heat treated at $\mathrm{T}=1073 \mathrm{~K}$.

It is noted that the value of the plateau is reached quickly; indicating that at this temperature the precipitation of secondary carbides is faster than for the previous temperature. Subsequently, it is observed that the hardness increases and decreases again. To understand this behavior, samples that have maximum and minimum hardness were compared in their microstructures; for example, samples aged during 480, 687, 1167 and $2007 \mathrm{~h}$ [points (a), (b), (c) y (d) in Figure 9]. It was found that microstructures having a minimum in hardness (points (a) and (c)) shown a region free of precipitates near the grain boundaries and interdendritic edges; while in those samples having higher hardness values, this region is almost negligible (points (b) and (d)). Vickers microhardness was determined in these regions free of precipitates (see Figure 10). A value of $\mathrm{Hv}=184 \pm 6$ was obtained by using a load of $10 \mathrm{~g}$. It is indicating that the region free of precipitates is softer than the rest. Probably, we are in the

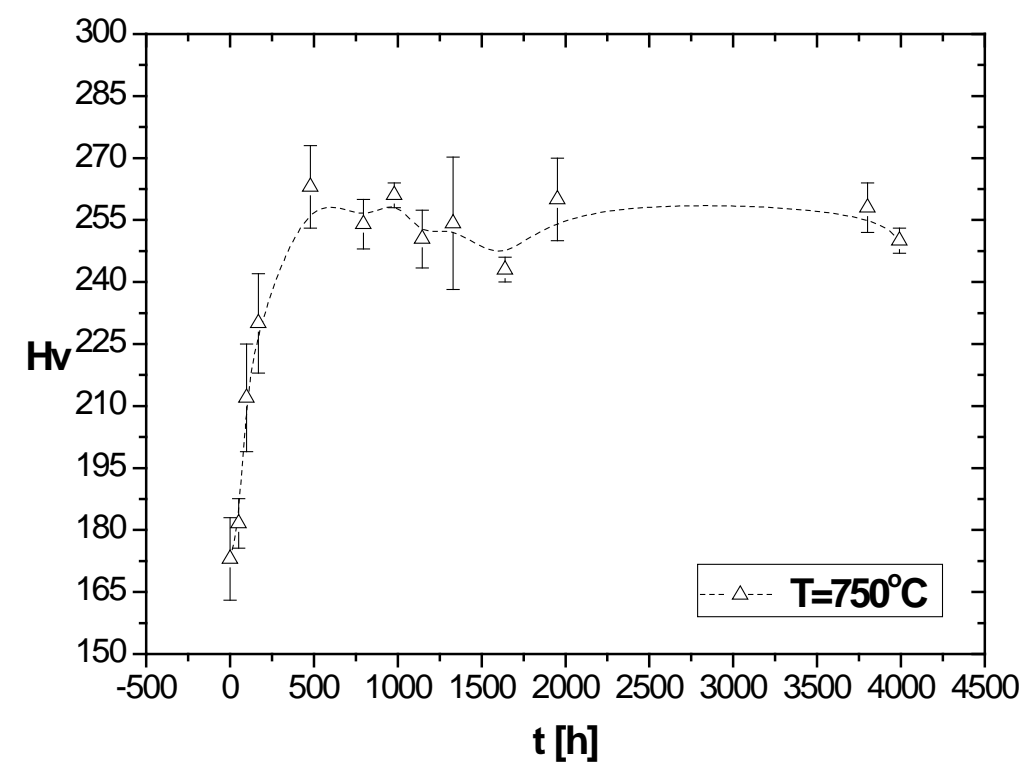

Figure 7. Vickers macrohardness evolution versus time of aging at $\mathrm{T}=1023 \mathrm{~K}$. 


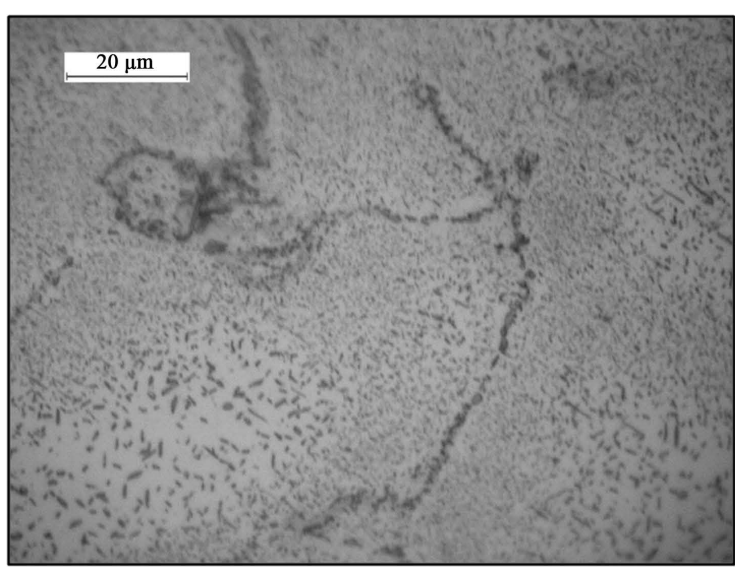

(a)

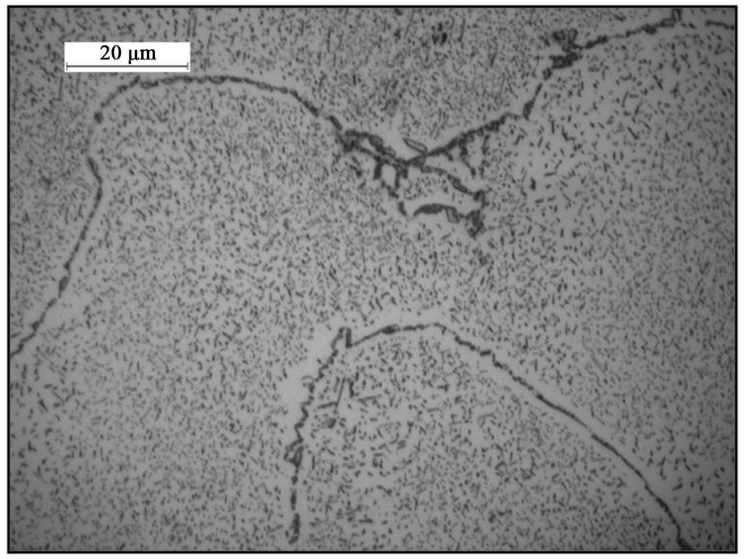

(c)

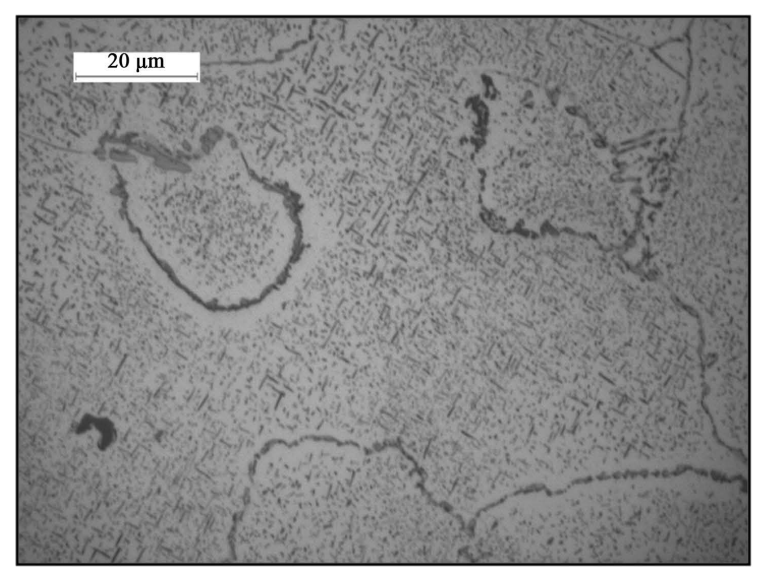

(b)

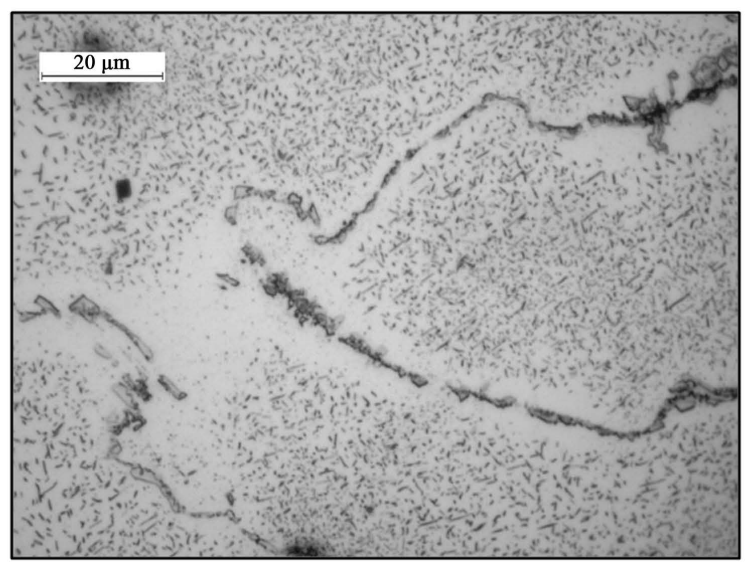

(d)

Figure 8. Microstructures of aged samples at $T=1073 \mathrm{~K}$ and different times $(1000 \times)$; (a) $t=480 \mathrm{~h},(\mathrm{~b}) \mathrm{t}=687 \mathrm{~h},(\mathrm{c}) \mathrm{t}=$ $1167 \mathrm{~h}$ and $(\mathrm{d}) \mathrm{t}=2007 \mathrm{~h}$.

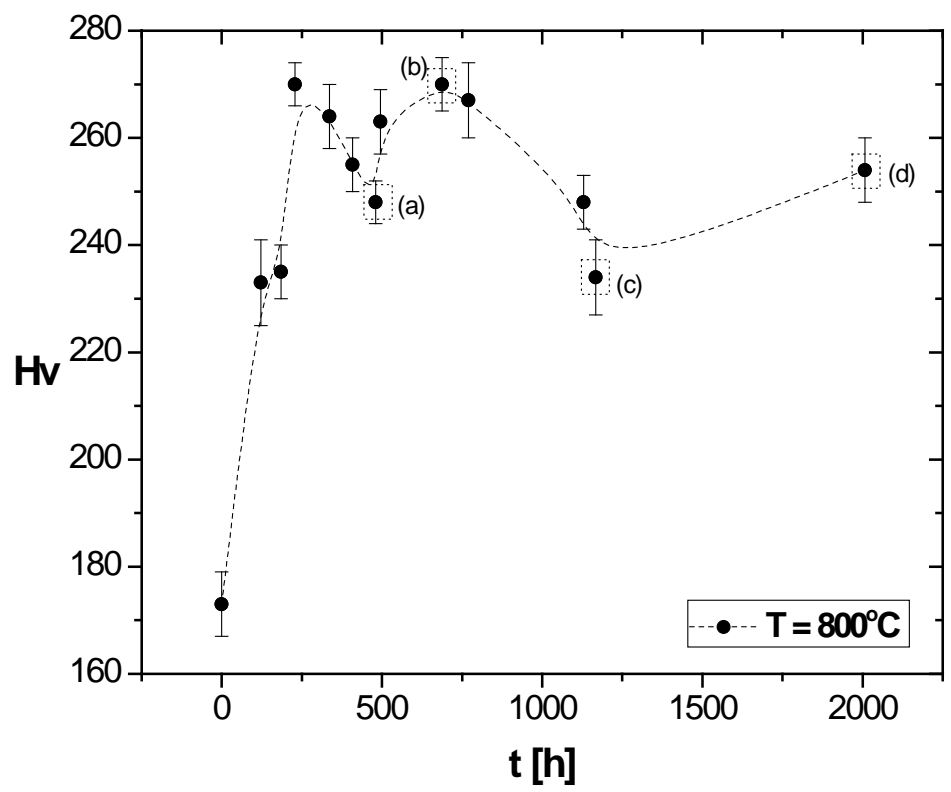

Figure 9. Vickers macrohardness as a function of aging time for samples heat treated at $\mathrm{T}=1073 \mathrm{~K}$. 


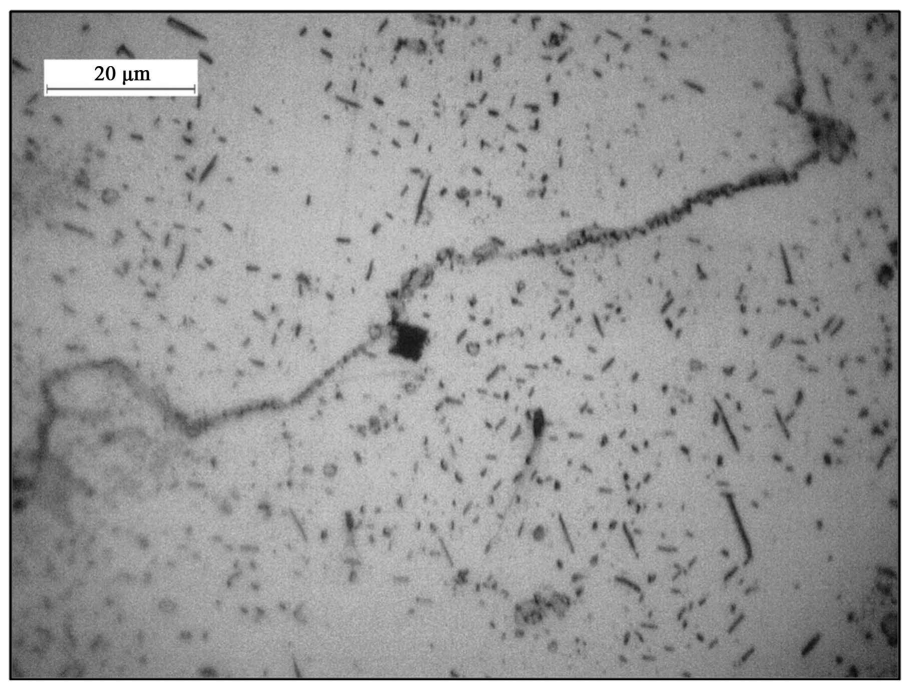

Figure 10. Vickers microhardness indentation in a depleted zone. Sample aged at $1173 \mathrm{~K}$ for $650 \mathrm{~h} .(1000 \times)$.

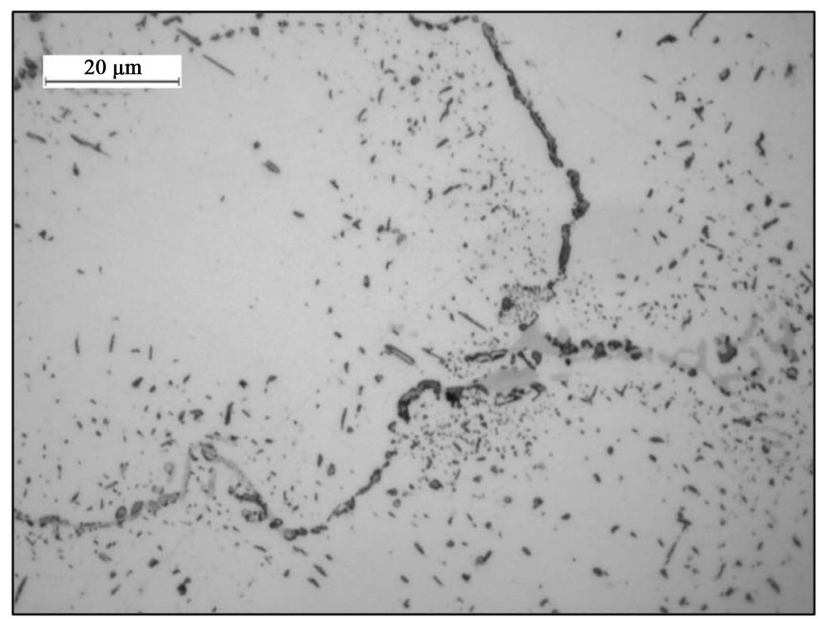

(a)

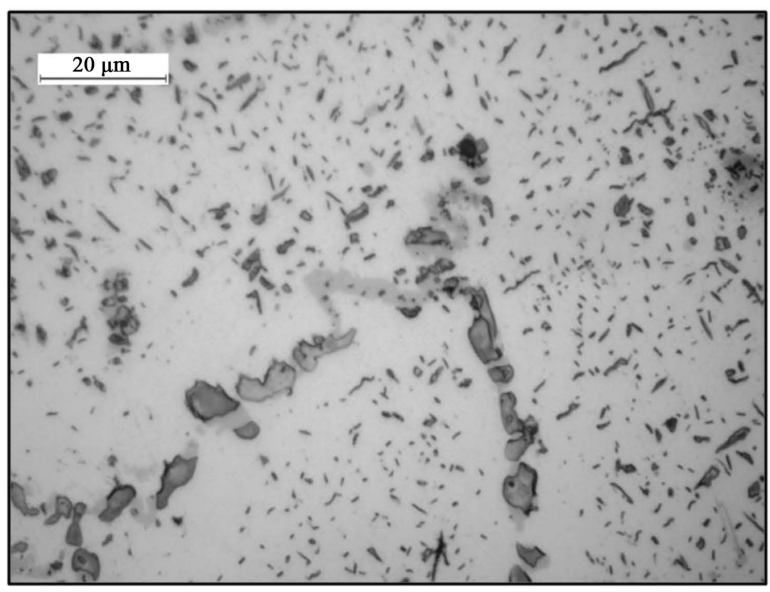

(b)

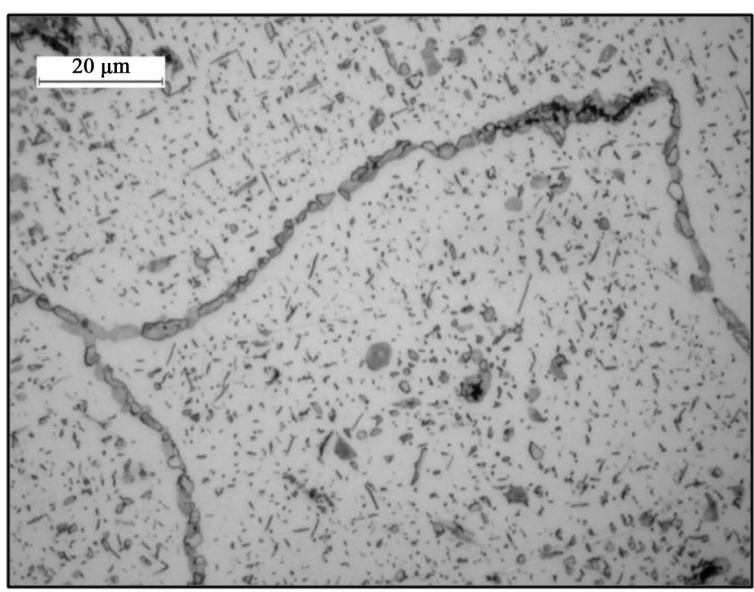

(c)

Figure 11. Microstructure evolution in aged samples at $\mathrm{T}=1123 \mathrm{~K}$ and different aging times $(1000 \times)$; (a) $\mathrm{t}=181 \mathrm{~h},(\mathrm{~b}) \mathrm{t}=$ $1145 \mathrm{~h},(\mathrm{c}) \mathrm{t}=3039 \mathrm{~h}$. 
presence of the phenomenon of sensitization. In these cases, chromium confers to steels, special alloys in general and to nickel alloys in particular a good resistance to intergranular attack and to intergranular stress corrosion cracking. The high chromium concentration destabilizes the solution by generating complex chromium carbides of type $\mathrm{Cr}_{3} \mathrm{C}_{2}, \mathrm{Cr}_{7} \mathrm{C}_{3}, \mathrm{Cr}_{23} \mathrm{C}_{6}$ and intermetallic phases which are rich in chromium. These compounds precipitate more or less quickly between 673 and $1173 \mathrm{~K}$ according to the content of carbon, chromium and molybdenum of ternary alloys Ni-Cr-Fe [13]-[18]. They often respect a sequence of heterogeneous nucleation, beginning with intergranular precipitation, then precipitation on incoherent twin boundaries and on the dislocations. Their growth, which is controlled by an intragranular thermally activated diffusional process, depends on the chromium content in the adjacent precipitates and on the matrix carbon content [19]-[26]. The consequence of the intergranular precipitation of these phases in general, and of the carbides in particular, is to create chromiumdepleted zones near the grain boundaries. These depleted zones get wider as the temperature and/or the aging duration is higher and reduces the local resistance to intergranular corrosion [27]. Sourmail [28], mention that $\mathrm{M}_{23} \mathrm{C}_{6}$ precipitation is generally related with intergranular corrosion, since these carbides causes a local depletion in chromium near the grain boundaries. This process is known as sensitization.

\subsection{Effect of Aging Treatment on the Microstructure at T $=1123 \mathrm{~K}$}

In this case, one can see how the morphology of the primary carbides is modified in function of the aging time and also how these begin to differentiate in their tonality through microstructures obtained by optical microscopy. In Figure 11, these differences can be observed.

\subsection{Evolution of the Hardness during the Aging at $1123 \mathrm{~K}$}

In Figure 12, Vickers macrohardness determinations for samples aged at $1123 \mathrm{~K}$ and different times are presented. As it can be seen, Vickers hardness gradually increases to a maximum value and then remains constant until a $3000 \mathrm{~h}$ aging. This behavior in the evolution of the hardness is somewhat different to that for the previous two temperatures of 1023 and $1073 \mathrm{~K}$. First, in this case we find that the maximum value is reached after a rather longer time than the two previous cases. Moreover, the Vickers hardness values are lower (maximum value $\mathrm{Hv}=$ about 230). This behavior can be explained by the change in the morphology observed at $\mathrm{T}=1123 \mathrm{~K}$ in the primary carbides, which shows that the eutectic type structure is disappearing and thus contributing to a softening hardness. Thus, the Vickers hardness values are lower at higher aging temperatures. Another additional contribution to softening of the microstructure is the size of the secondary precipitates and separation. In this regard, these no longer represent impenetrable barriers to dislocations and then the latter can cut the precipitates and move on sliding planes.

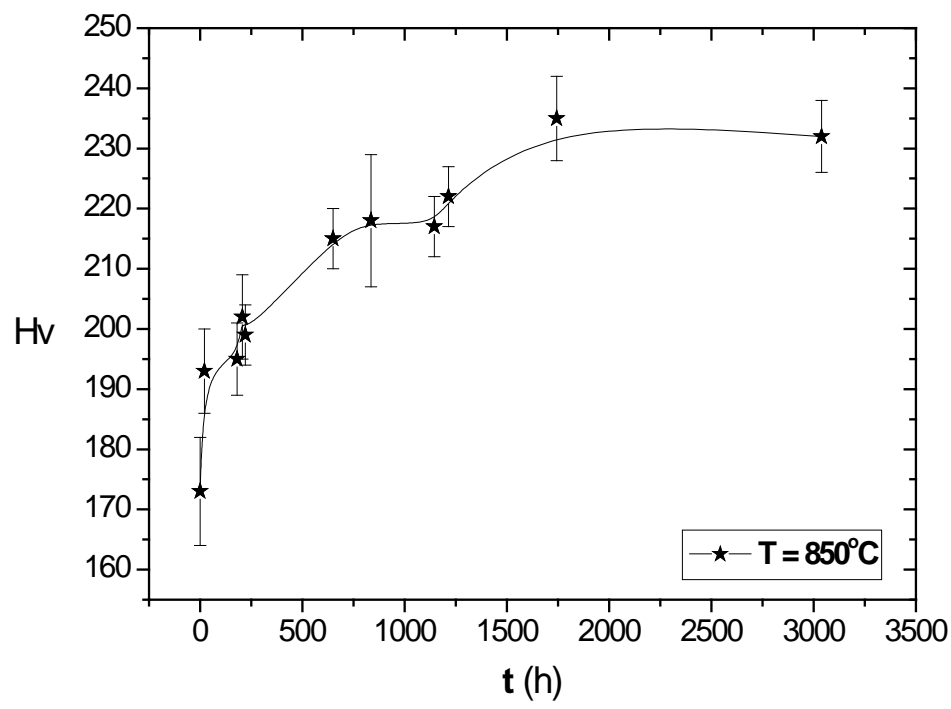

Figure 12. Vickers macrohardness as a function of aging time for samples heat treated at $\mathrm{T}=1123 \mathrm{~K}$. 


\subsection{Effect of Aging Treatment on the Microstructure at $\mathrm{T}=1173 \mathrm{~K}$}

In this case, there are no significant differences in the evolution observed in the microstructure at first, compared to the previous cases; however, for times of aging processes above about $500 \mathrm{~h}$ heterogeneities were observed in the microstructure, where the density of precipitates is too low and the free zones near grain boundaries precipitates is greater than the aged samples by time less than $500 \mathrm{~h}$. In Figure 13, such regions are indicated.

\subsection{Evolution of the Hardness during the Aging at $1173 \mathrm{~K}$}

In this case, Vickers macrohardness gradually increases from its value as cast to a maximum value of about 245 $\mathrm{Hv}$; and then it decreases slightly above the $500 \mathrm{~h}$ of aging, the hardness drops sharply to values of about 195 $\mathrm{Hv}$ and increases again in the last sample aged for up to $1000 \mathrm{~h}$ (see Figure 14). Note that, as temperature increase, aging times decrease because nucleation of precipitates take place in shorter times and the kinetic evolution of precipitation are faster.

This somewhat strange behavior, led us to repeat the heat treatment in these samples. Finally, this trend could be confirmed (that is, the sharp decrease in hardness). To understand this behavior effect, the samples microstructures were analyzed and compared, among those, the hardest and those which showed a sharp drop. It was found that the low hardness having these two samples is associated with the heterogeneous microstructure. Such heterogeneity comprises significant fractions of precipitated free area, mainly near the grain boundaries and regions of low density of precipitates inside dendrites regions. Vickers microhardness measurements were per-

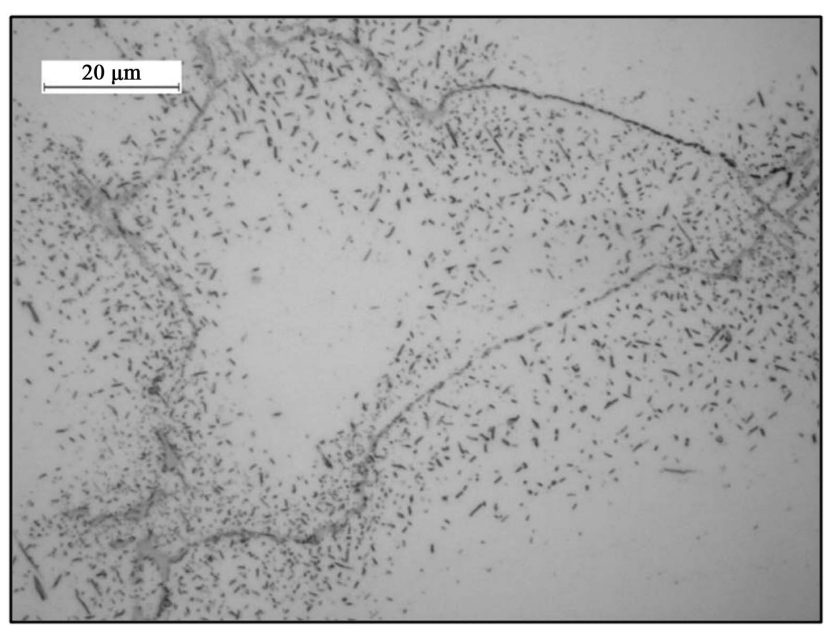

(a)

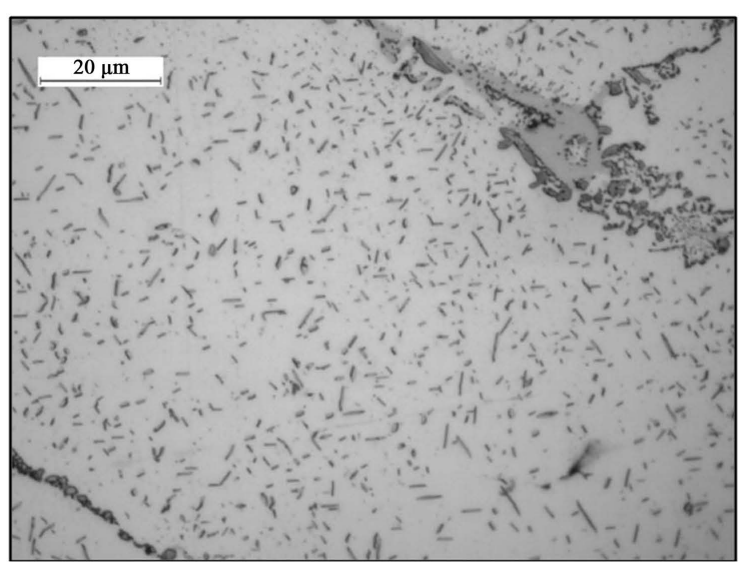

(b)

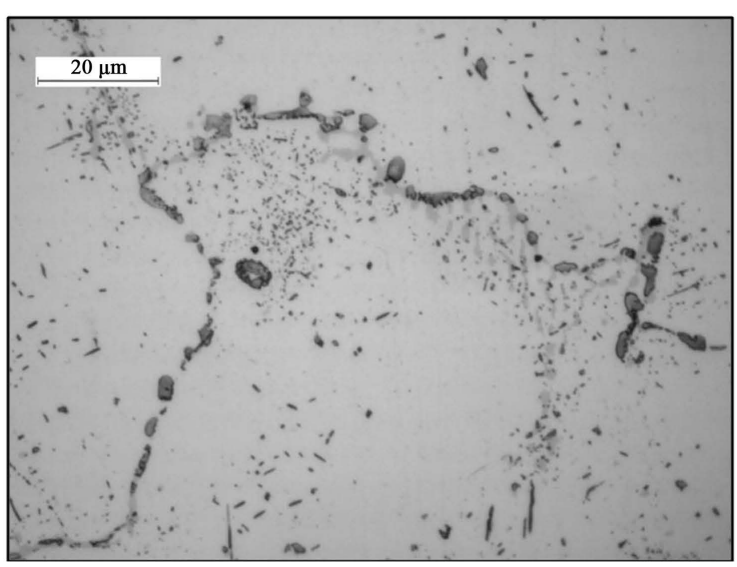

(c)

Figure 13. Microstructure evolution in aged samples at $\mathrm{T}=1173 \mathrm{~K}$ and different aging times $(1000 \times)$; (a) $\mathrm{t}=16 \mathrm{~h},(\mathrm{~b}) \mathrm{t}=$ $322 \mathrm{~h},(\mathrm{c}) \mathrm{t}=1000 \mathrm{~h}$. 


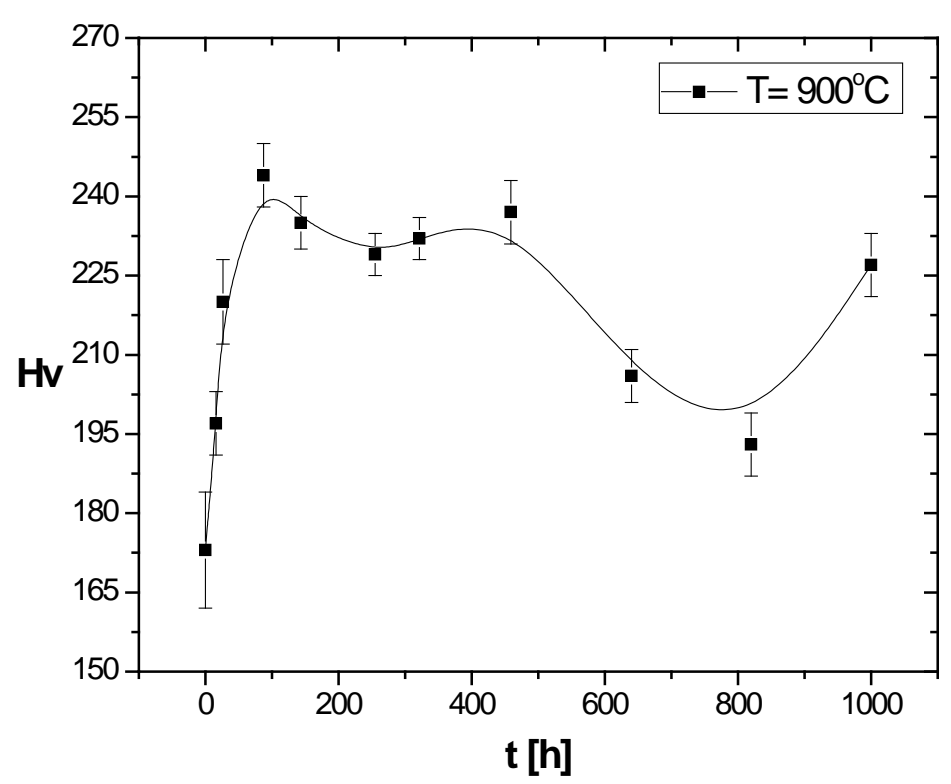

Figure 14. Vickers macrohardness as a function of aging time for samples heat treated at $\mathrm{T}=1173 \mathrm{~K}$.

formed with a load of $10 \mathrm{~g}$ in these regions and an average value of $\mathrm{Hv}=184 \pm 6$ was obtained; this indicates that these areas are soft in relation to the rest of the microstructure regions. Therefore, we can say that the fluctuations that occur in the hardness curves for temperatures of 1123 and $1173 \mathrm{~K}$ can be explained from the heterogeneities observed in the microstructures of samples that had lower hardness.

\section{Conclusions}

The conclusions of this study are summarized as follows:

- The microstructure as cast is dendritic type and is constituted by an austenitic matrix with carbides of two types; a) chromium carbides $\mathrm{M}_{23} \mathrm{C}_{6}$ type (eutectic) $(\mathrm{M}=\mathrm{Cr}, \mathrm{Ni}, \mathrm{Fe})$ and niobium carbides of $\mathrm{MC}$ type $(\mathrm{M}=$ $\mathrm{Nb})$; which are located in interdendritic edges and grain boundaries.

- In the aged samples at $1023 \mathrm{~K}$, secondary precipitation of fine carbides of $\mathrm{M}_{23} \mathrm{C}_{6}$ type, Vickers hardness increases to a saturation value and then remains approximately constant up to $3000 \mathrm{~h}$ of aging. In line with this, the microstructure does not change after reaching the saturation time or maximum hardness. At $1073 \mathrm{~K}$, the hardness gradually increases at a slower rate than $1023 \mathrm{~K}$. The microstructure in the aged samples shows changes in the morphology of the eutectic interdendritic primary precipitates and in secondary precipitates in the matrix. This could justify the behavior in the evolution of hardness.

- In the case of aged samples at 1123 and $1173 \mathrm{~K}$, it is observed that the hardness shows fluctuations with different aging times. It is found that they are associated with heterogeneity observed in the microstructure due to the presence of free regions near the grain boundaries and interdendritic edges. The microhardness values determined in these areas were lower than those found by macrohardness determinations; which it would indicate that these regions had lower mechanical strength.

\section{Acknowledgements}

This work was partially supported by Secretaría de Ciencia y Técnica de la Universidad Nacional del Sur (UNS), Laboratorio de Metalurgia y Tecnología Mecánica, Departamento de Ingeniería (UNS), Comisión de Investigaciones Científicas de la Provincia de Buenos Aires (CICPBA) and Consejo Nacional de Investigaciones Científicas y Técnicas (Conicet), República Argentina.

\section{References}

[1] Tillack, D.J. and Guthrie, J.E. (1998) Wrought and Cast Heat-Resistant Stainless Steels and Nickel Alloys for the Re- 
fining and Petrochemical Industries. Nickel Development Institute. Technical Series No. 10071.

[2] Roach, D.B. and Van Echo, J.A. (1982) Comparison of the Properties of the HK-40 and HP-45 Cast Heat-Resistant Alloys. Stainless Steel Castings, ASTM STP, 756, 275-312. http://dx.doi.org/10.1520/STP28447S

[3] Hou, W.T. and Honeycombe, R.W.K. (1985) Structure of Centrifugally Cast Austenitic Stainless Steels: Part 1 HK 40 as Cast and after Creep between $750^{\circ} \mathrm{C}$ and $1000^{\circ} \mathrm{C}$. Materials Science and Technology, 1, 385-389. http://dx.doi.org/10.1179/mst.1985.1.5.385

[4] Ibañez, R.A.P., de Almeida, L.H. and Le May, I. (1993) Effects of Si Content on the Microstructure of Modified-HP Austenitic Steels. Materials Characterization, 30, 243-249. http://dx.doi.org/10.1016/1044-5803(93)90071-3

[5] Blair, M.C. (1982) Cast Stainless Steels. Metals Handbook, 1, Materials Park, ASM, 908.

[6] Rodríguez, J., Haro, S., Velasco, A. and Colás, R. (2000) A Metallographic Study of Aging in Cast-Heat Resisting Alloy. Materials Characterization, 45, 25-32. http://dx.doi.org/10.1016/S1044-5803(00)00047-4

[7] de Almeida, L.H., Freitas Ribeiro, A. and Le May, I. (2003) Microstructural Characterization of Modified 25Cr-35Ni Centrifugally Cast Steel Furnace Tubes. Materials Characterization, 49, $219-229$. http://dx.doi.org/10.1016/S1044-5803(03)00013-5

[8] Voicu, R., Andrieu, E., Poquillon, D., Furtado, J. and Lacaze, J. (2009) Microstructure Evolution of HP40-Nb Alloys during Aging Under Air at $1000^{\circ}$ C. Materials Characterization, 60, 1020-1027. http://dx.doi.org/10.1016/j.matchar.2009.04.007

[9] Liu, C.J. and Chen, Y. (2011) Variation of the Microstructure and Mechanical Properties of HP40Nb Hydrogen Reformer Tube with Time at elevated Temperature. Materials \& Design, 32, 2507-2512. http://dx.doi.org/10.1016/j.matdes.2010.08.031

[10] Borjali, S., Allahkaram, S.R. and Khosravi, H. (2012) Effects of Working Temperature and Carbon Diffusion on the Microstructure of High Pressure Heat-Resistant Stainless Steel Tubes used in Pyrolysis Furnaces during Service Condition. Materials \& Design, 34, 65-73. http://dx.doi.org/10.1016/j.matdes.2011.07.069

[11] Sustaita-Torres, I.A., Haro-Rodríguez, S., Guerrero-Mata, M.P., de la Garza, M., Valdéz, E., Deschaux-Beaume, F. and Colás, R. (2012) Aging of a Cast 35Cr-45Ni Heat Resistant Alloy. Materials Chemistry and Physics, 133, 1018-1023. http://dx.doi.org/10.1016/j.matchemphys.2012.02.010

[12] Martin, J.W. (1980) Micromechanisms in Particle-Hardened Alloys. Cambridge University Press, Cambridge, 44.

[13] Stawström, C. and Hillert, M. (1969) An Improved Depleted Theory of Intergranular Corrosion of 18/8 Stainless Steel. Journal: Iron and Steel Institute, 207, 77-85.

[14] Kai, J.J., Yu, G., Tsai, C.H., Liu, M.N. and Yao, S.C. (1989) The Effects of Heat Treatment on the Chromium Depletion, Precipitate Evolution, and Corrosion Resistance of Inconel Alloy 690. Metallurgical and Materials Transactions A, 20, 2057-2067. http://dx.doi.org/10.1007/BF02650292

[15] Was, G.S., Tischner, H.H. and Latanision, R.M. (1981) The Influence of Thermal Treatment on the Chemistry and Structure of Grain Boundaries in Inconel 600. Metallurgical and Materials Transactions A, 12, 1397-1408. http://dx.doi.org/10.1007/BF02643684

[16] Borello, A., Casadio, S., Saltelli, A. and Scibono, G. (1981) Susceptibility to the Intergranular Corrosion of Alloy 800. Corrosion, 37, 498-505. http://dx.doi.org/10.5006/1.3580797

[17] Mayo, W.E. (1997) Predicting IGSCC IGA Susceptibility of Ni-Cr-Fe Alloys by Modeling of Grain-Boundary Chromium Depletion. Materials Science and Engineering: A, 232, 129-139. http://dx.doi.org/10.1016/S0921-5093(97)00110-X

[18] Was, G.S. and Kruger, R.M. (1985) A Thermodynamic and Kinetic Basis for Understanding Chromium Depletion in Ni-Cr-Fe Alloys. Acta Metallurgica, 33, 841-854. http://dx.doi.org/10.1016/0001-6160(85)90108-7

[19] Pumphrey, P.H. and Edington, J.W. (1974) The Structure of the Semicoherent Interface between Grain Boundary Nucleated $\mathrm{M}_{23} \mathrm{C}_{6}$ and Austenitic Stainless Steel. Acta Metallurgica, 22, 89-94. http://dx.doi.org/10.1016/0001-6160(74)90128-X

[20] Beckitt, F.R. and Clark, B.R. (1967) The Shape and Mechanism of Formation of $\mathrm{M}_{23} \mathrm{C}_{6}$ Carbide in Austenite. Acta Metallurgica, 15, 113-129. http://dx.doi.org/10.1016/0001-6160(67)90159-9

[21] Singhal, L.K. and Martin, J.W. (1968) The Nucleation and Growth of Widmannstätten $\mathrm{M}_{23} \mathrm{C}_{6}$ Precipitation in an Austenitic Stainless Steel. Acta Metallurgica, 16, 1159-1165. http://dx.doi.org/10.1016/0001-6160(68)90050-3

[22] Da Casa, C., Nileshwar, V.B. and Melford, D.A. (1969) $\mathrm{M}_{23} \mathrm{C}_{6}$ Precipitation in Unstabilized Austenitic Stainless Steel. Journal: Iron and Steel Institute, 207, 1325-1332.

[23] Lewis, M.H. and Hattersley, B. (1965) Precipitation of $\mathrm{M}_{23} \mathrm{C}_{6}$ in Austenitic Steels. Acta Metallurgica, 13, $1159-1168$. http://dx.doi.org/10.1016/0001-6160(65)90053-2 
[24] Adamson, J.P. and Martin, J.W. (1974) A Microanalytical Study of $\mathrm{M}_{23} \mathrm{C}_{6}$ Carbides as a Function of Ageing Time in Nb-Bearing Austenitic Steels. Metallography, 7, 397-402. http://dx.doi.org/10.1016/0026-0800(74)90040-8

[25] Singhal, L.K. and Martin, J.W. (1967) The Growth of $\mathrm{M}_{23} \mathrm{C}_{6}$ Carbide on Incoherent Twin Boundaries in Austenite. Acta Metallurgica, 15, 1603-1610. http://dx.doi.org/10.1016/0001-6160(67)90134-4

[26] Hillert, M. and Lagneborg, R.J. (1971) Discontinuous Precipitation of $\mathrm{M}_{23} \mathrm{C}_{6}$ in Austenitic Steels. Journal of Materials Science, 6, 208-212. http://dx.doi.org/10.1007/BF00550014

[27] Tawancy, H.M. (2009) Degradation of Mechanical Strength of Pyrolysis Furnace Tubes by High-Temperature Carburization in a Petrochemical Plant. Engineering Failure Analysis, 16, 2171-2178. http://dx.doi.org/10.1016/j.engfailanal.2009.02.009

[28] Sourmail, T. (2001) Precipitation in Creep Resistant Austenitic Stainless Steels. Materials Science and Technology, 17, 1-14. http://dx.doi.org/10.1179/026708301101508972 